\title{
Coronary Thrombolysis and Infarct Size Reduction After Intravenous Infusion of Recombinant Tissue-type Plasminogen Activator in Nonhuman Primates
}

\author{
W. Flameng, F. Van de Werf, J. Vanhaecke, M. Verstraete, and D. Collen \\ Laboratory of Cardiovascular Surgery, Laboratory of Experimental Cardiology, \\ and Center for Thrombosis and Vascular Research, University of Leuven, Belgium
}

\begin{abstract}
Occlusive thrombus was produced by thrombin-induced coagulation in the left anterior descending coronary artery (LAD) of 16 open-chest baboons. In six control animals, occlusive thrombosis persisting over a period of $4 \mathrm{~h}$ as evidenced by coronary arteriography resulted in large transmural infarction (63.1 $\pm 3.5 \%$ of the perfusion area). In 10 animals, tissue-type plasminogen activator obtained by recombinant DNA technology (rt-PA) was infused systemically at a rate of $1,000 \mathrm{IU}$ (10 $\mu g) / k g$ per $\mathrm{min}$ for $30 \mathrm{~min}$ after $30-80 \mathrm{~min}$ of coronary thrombosis. Reperfusion occurred within $30 \mathrm{~min}$ in nine animals. In one animal, intravenous infusion was followed by an intracoronary infusion at the same rate, which resulted in thrombolysis within $8 \mathrm{~min}$. In the rt-PA group, mean duration of occlusion before reperfusion was $77 \pm 24 \mathrm{~min}$. Reocclusion occurred in one animal. Recanalization resulted in an overall reduction of infarct size $(37.8 \pm 5.9 \%, P<0.05$ versus controls). Residual infarction was related to the duration of occlusion ( $r$ $=0.80, P<0.01)$. Reperfusion was associated with reduced reflow. Myocardial blood flow in the perfusion area of the LAD was only $70 \%$ of normal after $4 \mathrm{~h}$ despite perfect angiographic refilling.

The infusion of rt-PA was not associated with systemic activation of the fibrinolytic system, fibrinogen breakdown, or clinically evident bleeding.

It is concluded that intravenous infusion of rt-PA may recanalize thrombosed coronary vessels without inducing systemic lysis. The extent of residual infarction is closely related to the duration of coronary artery occlusion before thrombolysis.
\end{abstract}

\section{Introduction}

Despite the multifactorial pathogenesis of transmural myocardial infarction, coronary thrombosis seems to be the final common pathway converting chronic coronary artery disease to acute infarction (1). Indeed, coronary thrombosis was demonstrated by arteriography and confirmed by surgical exploration within $6 \mathrm{~h}$ from the onset of symptoms of transmural infarction in $\sim 80 \%$ of the patients (1). Consequently, thrombolytic therapy of acute myocardial infarction is now extensively investigated as a way to improve myocardial function, and possibly decrease cardiac mortality.

Address correspondence to Dr. Collen, Center for Thrombosis and Vascular Research, Department of Medical Research, K.U. LeuvenCampus Gasthuisberg, Herestraat 49, B-3000 Leuven, Belgium.

Received for publication 17 October 1983 and in revised form 31 August 1984.

J. Clin. Invest.

(C) The American Society for Clinical Investigation, Inc.

0021-9738/85/01/0084/07 $\$ 1.00$

Volume 75 , January $1985 ; 84-90$
Therapeutic thrombolysis can be achieved by agents that activate endogenous plasminogen to plasmin. However, the available plasminogen activators urokinase and streptokinase have a strong systemic lytic effect, which results in breakdown of the hemostatic system and a bleeding tendency. Tissue-type plasminogen activator (t-PA) ${ }^{1}$ was recently obtained in significant amounts from the culture medium of a human melanoma cell line (2). This activator requires fibrin as a cofactor for plasminogen activation and thus induces thrombolysis with minimal systemic lytic effect. Using this material, Bergmann et al. (3) showed that systemic infusion in dogs resulted in rapid thrombolysis of a coronary thrombus and reduction of metabolically compromised myocardium.

Pennica et al. (4) cloned and expressed the t-PA gene, and Van de Werf et al. (5) and Gold et al. (6) demonstrated that the recombinant tissue-type plasminogen activator (rt-PA) had thrombolytic activities similar to the natural t-PA in dogs with experimental occlusive coronary thrombosis.

In this study, we used a primate species (baboon) to establish whether high-dose systemic infusion of rt-PA can induce coronary thrombolysis without being associated with systemic fibrinolytic activation, and to evaluate the beneficial effect of reperfusion on the ischemic ventricle. Therefore, coronary angiography was supplemented with measurements of regional myocardial blood flow and determination of infarct size $4 \mathrm{~h}$ after the coronary occlusion.

\section{Methods}

16 baboons (Papio anubis) of either sex, weighing between 9.7 and $14.5 \mathrm{~kg}$, were anesthetized with $10 \mathrm{mg} \cdot \mathrm{kg}^{-1} \mathrm{ketamine}$ hydrochloride (ketalar; Duphar, Amsterdam, The Netherlands) and $0.06 \mathrm{mg} \cdot \mathrm{kg}^{-1}$ atropin intramuscularly after premedication with $5 \mathrm{mg}$ diazepam (valium; Hoffmann-LaRoche, Nutley, NJ) intramuscularly. After endotracheal intubation, the lungs were ventilated using a respirator (Bird Mark 7; Bird Corporation, Palm Springs, CA). Anesthesia was maintained with $30 \mathrm{mg} \cdot \mathrm{kg}^{-1}$ pentobarbital (nembutal; Abbott Laboratories, North Chicago, IL) intravenously. Blood gas analysis was performed using a pH blood gas microanalyser (166; Corning Glass Works, Corning, NY) repeatedly throughout the experiment. Catheters were inserted into the descending aorta and the right atrium via the right femoral artery and vein for the measurement of aortic and central venous pressure. Via the left carotid artery, a catheter ( $7 \mathrm{~F}$ Sones, USCI, Billerica, MA) was inserted and angiography of the right and left coronary arteries was made. Next a sternotomy was performed and the heart was suspended in a pericardial cradle. A small tube was

1. Abbreviations used in this paper: AoP, aortic pressure; $\mathrm{I} / \mathrm{P}$, infarct size calculated as percent of the mass of the perfusion bed of the occluded artery; LAD, left anterior descending coronary artery; LAP, left atrial pressure; $\mathrm{MBF}$, myocardial blood flow; $\mathrm{P} / \mathrm{LV}$, area at risk expressed as percentage of the left ventricular mass; rt-PA, recombinant tissue-type plasminogen activator; TM, tracer microspheres; t-PA, tissue-type plasminogen activator; TTC, triphenyl tetrazolium chloride. 
inserted into the left atrium to measure left atrial pressure and to inject tracer microspheres (TM) (NEN Chemicals GmbH, Dreieich, W. Germany). For calibrating the TM values, arterial blood was withdrawn at a constant speed from the descending aorta using a multispeed transmission pump (Harvard Apparatus Co., Inc., S. Natick, MA). The left anterior descending coronary artery (LAD) was dissected free over a small segment to produce a coronary thrombosis as described below.

As hemodynamic parameters, systolic and diastolic aortic pressure (AoP), left atrial pressure (LAP), electrocardiogram lead II, and heart rate were registered on a multichannel recorder (Siemens Corp., Iselin, NJ) throughout the experiment.

Experimental protocol. $10 \mathrm{~min}$ after sternotomy and preparation of the LAD, but before coronary thrombosis, a first injection of TM was made in the left atrium. Thereafter, a $1-\mathrm{cm}$-long LAD segment was ligated at its proximal and distal end using $7 / 0$ prolene snares, and thrombin $(\sim 10 \mu \mathrm{l}$ of $100 \mathrm{NIH} \mathrm{U/ml})$ was injected in the isolated vessel segment. The segment was repeatedly crushed with small forceps. This resulted in a localized thrombus occluding the LAD. After 15 min the prolene snares were released and coronary angiography was performed to confirm complete obstruction of the LAD. 20 min after LAD occlusion, a second TM injection was made for the quantitation of regional myocardial blood flow. Between 30 and $80 \mathrm{~min}$ after coronary thrombosis, $\mathrm{rt}-\mathrm{PA}\left(1,000 \mathrm{IU} \cdot \mathrm{kg}^{-1} \mathrm{~min}^{-1}\right)$ was infused for 30 min via the right brachial vein in 10 baboons (see Table I). Control coronary angiography was performed at 10 -min intervals. Upon complete recanalization of the LAD, a third injection of TM was made. Immediately after thrombolysis, the animals were heparinized to prevent rethrombosis. During the rt-PA infusion, blood samples were collected from the left brachial vein into $0.01 \mathrm{M}$ citrate to determine fibrinogen, plasminogen, $\alpha_{2}$-antiplasmin, and t-PA level as previously described (7). Thrombolysis was complete within $30 \mathrm{~min}$ in 9 of the 10 animals. In the baboon with remaining occlusive thrombus, rt-PA was further infused in the left coronary ostium via the Sones catheter. The other six baboons served as controls. They underwent the same experimental procedure except for the rt-PA infusion. They were heparinized $60 \mathrm{~min}$ after LAD occlusion.

During LAD occlusion and/or reperfusion, all animals received 50 $\mu \mathrm{g} \cdot \mathbf{k g}^{-1}$ lidocain (xylocain; Astra Scientific International, Inc., Santa Clara, CA) intravenously. $4 \mathrm{~h}$ after acute occlusion of the LAD, a fourth TM injection was made in all animals and a final coronary angiography was performed. Then the animals were sacrificed by an overdose of pentobarbital and the heart was removed. Both left and right coronary ostia were cannulated as well as the LAD distal from the site of thrombosis. The LAD area was perfused with Ringer's

Table I. Infusion of rt-PA in 10 Baboons

\begin{tabular}{clll}
\hline Baboon no. & $\begin{array}{l}\text { Duration of LAD } \\
\text { occlusion before } \\
\text { start rt-PA }\end{array}$ & $\begin{array}{l}\text { Time to } \\
\text { reperfusion from } \\
\text { start of rt-PA } \\
\text { infusion }\end{array}$ & $\begin{array}{l}\text { Total } \\
\text { occlusion time }\end{array}$ \\
\hline & $\min$ & $\min$ & $\min$ \\
20 & 30 & 8 & 38 \\
21 & 30 & 15 & 45 \\
18 & 45 & 30 & 75 \\
11 & 60 & 8 & 68 \\
10 & 60 & 12 & 72 \\
13 & 60 & 24 & 84 \\
8 & 60 & $30(+8$ min IC) & 98 \\
$15^{*}$ & 75 & 30 & 105 \\
19 & 77 & 25 & 102 \\
14 & 80 & 28 & 108 \\
\hline
\end{tabular}

* Rethrombosis within $10 \mathrm{~min}$. IC, intracoronary application. solution while the ostia were perfused at the same pressure with a mixture of Ringer's solution and Evans blue. 3 min later, the nonLAD area was perfused with a mixture of Evans blue and glutaraldehyde $2 \%$ for $10 \mathrm{~min}$. The hearts were cut in slices $(5 \mathrm{~mm}$ thick) perpendicular to the apex-base axis. These slices were incubated in triphenyl tetrazolium chloride (TTC). With this technique, the Evans blue colored the non-LAD area blue. TTC colored viable tissue red and infarcted tissue white. Calibrated pictures were made from each slice, and the area of the LAD perfusion bed, the area occupied by infarcted tissue, and the total area of the left ventricle were determined by planimetry using a Quantimet-900. Infarct size was calculated as percentage of the perfusion area of the LAD (I/P). The area at risk was expressed as a percentage of the left ventricular mass ( $P / L V)$.

Regional myocardial blood flow was measured with radioactive tracer microspheres, as described before (8). The left ventricular slices were unrolled and divided into subepicardial and subendocardial samples ( $\pm 1-\mathrm{g}$ tissue blocks). Gamma spectrometry was carried out on all tissue and blood samples (9) with a multichannel analyzer (ND66, Nuclear Data, Inc., Schaumburg, IL) and computer terminal (Nuclear Data, Inc.). Four differently labeled microspheres were used: Ce-141, $\mathrm{Sn}-113, \mathrm{Ru}-103$, and Nb-95.

\section{Results}

Coronary angiographic findings. Coronary thrombolysis was achieved in all 10 baboons that received rt-PA (Table I). Angiographic evidence of clot lysis with complete reopening of the LAD was seen in 9 out of 10 animals during the 30min period of systemic rt-PA infusion. In one animal, thrombolysis was not achieved within the 30 -min period of intravenous rt-PA infusion but occurred within $8 \mathrm{~min}$ of subsequent intracoronary administration. Reocclusion of the LAD occurred in one experiment. Fig. 1 shows angiographic evidence of thrombolysis in a typical experiment. In the control group, complete occlusion of the LAD persisted throughout the experiment in all six animals.

Regional myocardial blood flow (MBF). Acute occlusion of the LAD resulted in a severe reduction of myocardial blood flow in its perfusion area (Fig. 2). This relatively low collateral flow (15.6 and $15.7 \%$ of flow to the non-occluded area in the two groups) persisted in the control group with permanent LAD occlusion (Fig. 2). Lysis of the coronary thrombus that occurred after $77 \mathrm{~min}$ (between 38 and $108 \mathrm{~min}$ ) resulted in a reactive hyperemia in the LAD area in the majority of animals. In two baboons, however, severely reduced reflow was found. For the group as a whole (the animal that developed reocclusion was excluded), mean myocardial blood flow in the LAD area was $147 \mathrm{ml} \cdot \mathrm{min}^{-1} \cdot 100 \mathrm{~g}^{-1}$ vs. $158 \mathrm{ml} \cdot \mathrm{min}^{-1} \cdot 100$ $\mathrm{g}$ in the non-LAD area (Fig. 2). $2.5 \mathrm{~h}$ later, however, reduced reflow was found in six out of nine animals despite perfect angiographic refilling. The ratio of $\mathrm{MBF}$ in the $\mathrm{LAD}$ region versus the non-LAD region was only $70 \%$.

Effects of reperfusion on infarct size. Occlusion of the LAD for $4 \mathrm{~h}$ resulted in large transmural infarction in all control baboons. The mean percentage of the perfusion area of the occluded artery showing infarction (I/P) was $63.1 \pm 3.5 \%$ (SEM). In the reperfused baboons, the percent of infarcted tissue was significantly lower than in the controls: $37.8 \pm 8.9 \%(P<0.05)$ (Fig. 3). A significant correlation was found between residual infarction (I/P) and the duration of coronary artery occlusion $(r=0.80, P<0.01)$ (Fig. 4). The animal that developed a reocclusion had an infarct size of $48 \%$ and was excluded from the results of the reperfused group. 

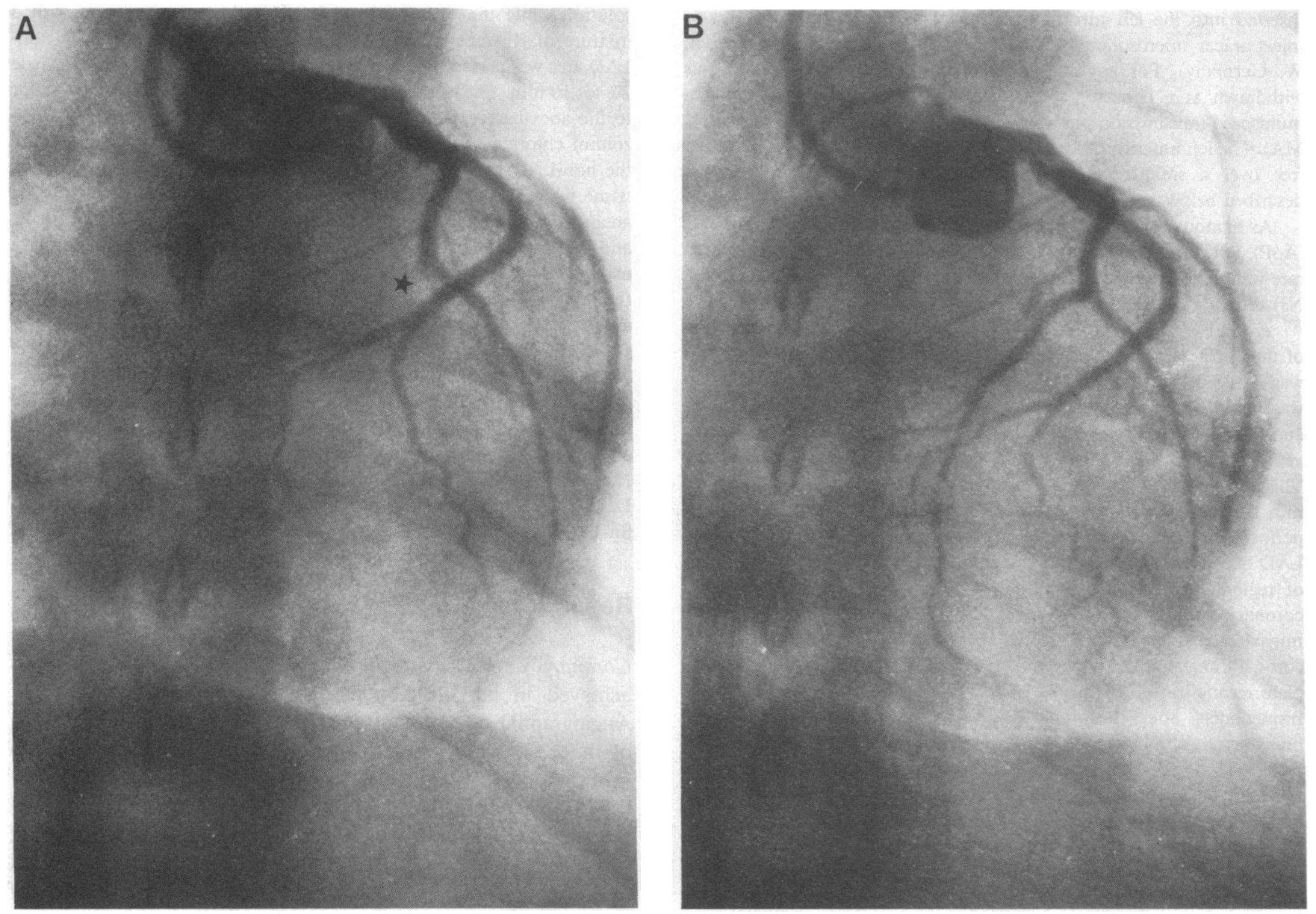

Figure 1. Coronary angiography before and after infusion of rt-PA in a baboon with thrombotic occlusion of the LAD. $(A)$ Angiography after thrombotic occlusion of the LAD (indicated by asterisk). (B) Angiography after reperfusion by intravenous administration of rt-PA.

Cross sections of the heart of a control and a reperfused baboon are shown in Fig. 5. In the controls, none of the infarctions were hemorrhagic (Table II). In the reperfused

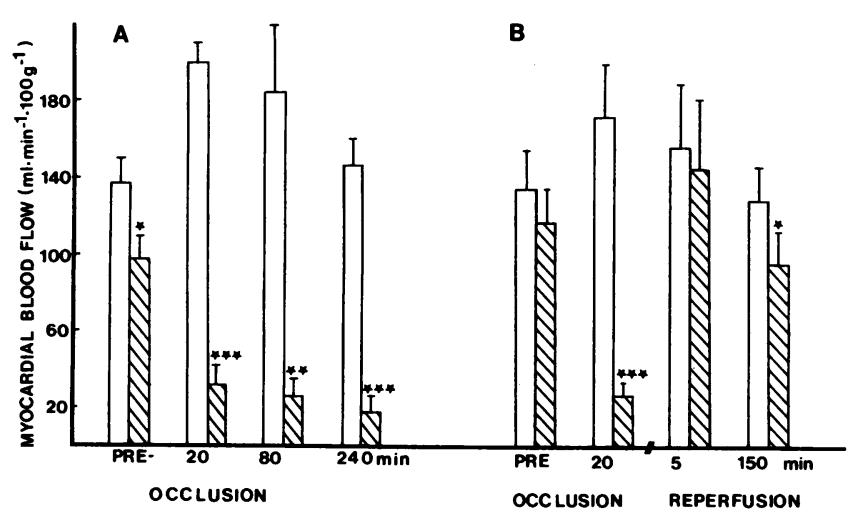

Figure 2. Regional MBF before and after LAD occlusion and after reperfusion. $(A)$ Control group without reperfusion $(n=6)$. $(B)$ Group with rt-PA infusion $(n=9)$. The results represent mean \pm SEM. Asterisks indicate significant changes from the corresponding MBF in the control region $\left({ }^{*} P<0.05 ;{ }^{* *} P<0.005 ;{ }^{* * *} P\right.$ $<0.001$ ). Open bars, control region; hatched bars, area at risk (LAD). baboons, the occurrence of postreperfusion myocardial infarction was directly related to the duration of occlusion. After 68 min of LAD thrombosis, reperfusion induced hemorrhage in six out of seven animals. Also, the extent of hemorrhage increased proportionally with the duration of occlusion (Table II). Characteristically, the hemorrhage was located in the midwall and never extended outside the infarct into viable myocardium. In fact, the infarction was never transmural in the reperfusion baboons. It was always located in the midwall, either very patchy in animals with short occlusion times or more homogeneous in those with longer occlusion times.

The volume of the perfusion area of the occluded artery (P/LV) was not different between the rt-PA group (27.6 $\pm 2.4 \%)$ and the control group $(24.3 \pm 1.5 \%)(P>0.05)$.

Hemodynamic changes. In the animals with permanent LAD occlusion, the main hemodynamic parameters (heart rate, AoP, and LAP) remained essentially unchanged throughout the experiment (Fig. 6). In the reperfused baboons, heart rate and mean AoP decreased slightly after thrombolysis, but this decrease did not seem to be hemodynamically relevant. In the reperfused animals, the incidence of arrhythmias (ventricular ectopic beats, runs of ventricular tachycardia) was higher than in the group with permanent LAD occlusion.

Throughout the experiments, blood $\mathrm{pH}, \mathrm{pO}_{2}, \mathrm{pCO}_{2}, \mathrm{HCO}_{3}$, and total $\mathrm{CO}_{2}$ were kept within normal limits. 


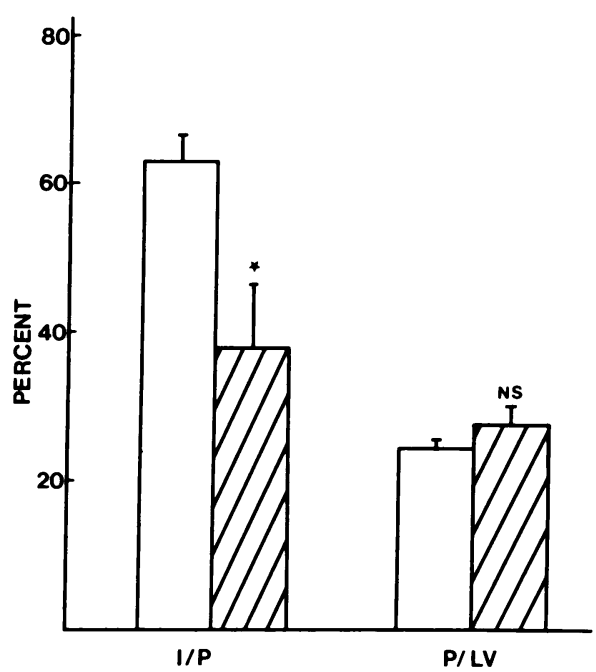

Figure 3. Effect of reperfusion on infarct size. The values represent mean \pm SEM of the mass of infarcted tissue, expressed as percent of the mass of the perfusion bed of the occluded artery $(\mathrm{I} / \mathrm{P})$, and mean \pm SEM of the mass of the perfusion bed of the occluded artery, expressed as percent of the mass of the left ventricle $(\mathrm{P} / \mathrm{LV})$. Asterisk indicates significant difference with corresponding values obtained in the control group $(P<0.01)$. NS, $P>0.05$.

Changes in hemostatic parameters. During infusion of rtPA, a steady-state plasma level of $550 \pm 70 \mathrm{ng} / \mathrm{ml}$ was maintained. However, this was not associated with systemic fibrinolytic activation because after the infusion, the fibrinogen, the $\alpha_{2}$-antiplasmin, and the plasminogen levels had not significantly changed compared with the control group (Fig. 7).

\section{Discussion}

This report confirms and extends to primates the finding that rt-PA can produce coronary thrombolysis without significant

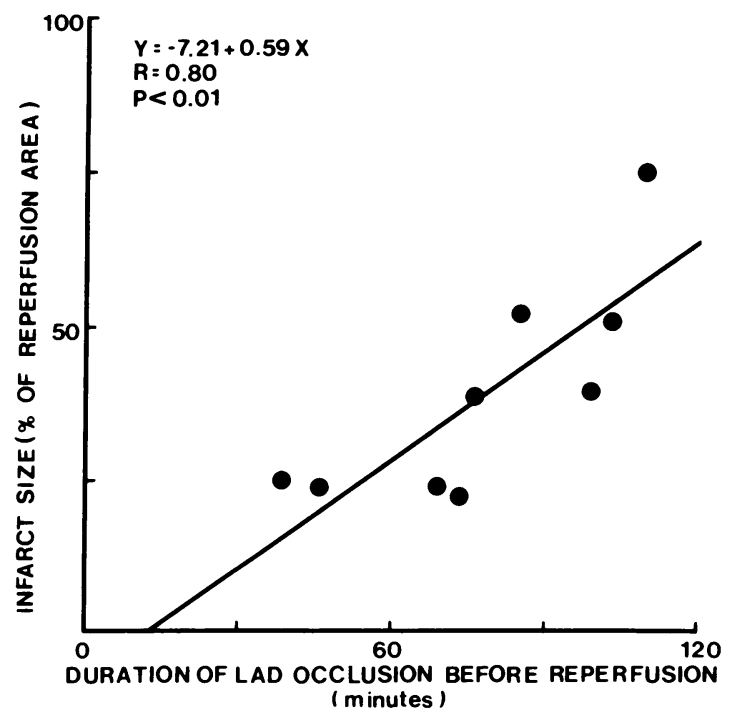

Figure 4. Correlation between the duration of LAD occlusion before reperfusion and infarct size (expressed as a percent of the mass of the perfusion bed of the LAD). A linear correlation was found with a correlation coefficient $(r)$ of $0.80(P<0.01)$. The baboon that developed a rethrombosis after successful thrombolysis was not included.
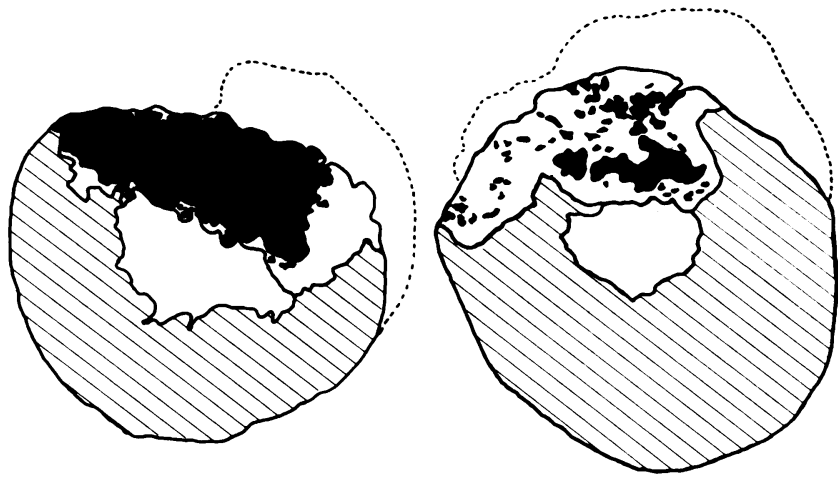

Figure 5. Schematic drawings of cross sections of the hearts of baboons without (left) and after (right) reperfusion with rt-PA of the LAD. Hatched zones, perfusion area of the right coronary artery and circumflex branch of left coronary artery; white zones, perfusion area of LAD with viable tissue (red color on cross section); black zones, area with infarction (white color on cross section).

systemic fibrinolytic effects. The results indicate that timely reopening of an occluded coronary thrombus has a profound beneficial effect on infarct size. Indeed, there seems to be a good correlation $(r=0.80)$ between time to reperfusion and infarct size. Consequently, our results may be relevant for the thrombolytic therapy in patients with evolving myocardial infarction.

The preservation of ischemic myocardium by early revascularization in animal models is a controversial issue (10-17). Variability in experimental results may be due to many factors, including differences in collateral flow within (18) and between

Table II. Infarctions in Control and Reperfused Baboons

\begin{tabular}{llll}
\hline Baboon no. & $\begin{array}{l}\text { Total } \\
\text { occlusion time }\end{array}$ & Hemorrhage & Hemorrhage \\
\hline min & $\%$ of IS & \% of $P A$
\end{tabular}

Control group

$\begin{array}{rlll}6 & 240 & 0.0 & 0.0 \\ 9 & 240 & 0.0 & 0.0 \\ 7 & 240 & 0.0 & 0.0 \\ 12 & 240 & 0.0 & 0.0 \\ 16 & 240 & 0.0 & 0.0 \\ 17 & 240 & 0.0 & 0.0\end{array}$

rt-PA group

$\begin{array}{rrrr}20 & 38 & 0.0 & 0.0 \\ 21 & 45 & 0.0 & 0.0 \\ 11 & 68 & 26.9 & 6.1 \\ 10 & 72 & 38.0 & 8.0 \\ 18 & 75 & 0.0 & 0.0 \\ 13 & 84 & 31.8 & 12.1 \\ 8 & 98 & 21.4 & 8.2 \\ 19 & 102 & 76.3 & 20.3 \\ 14 & 108 & 81.8 & 18.5 \\ 15^{*} & 105^{*} & 0.0 & 0.0\end{array}$

IS, infarct size; PA, perfusion area.

* Rethrombosis within $10 \mathrm{~min}$. 


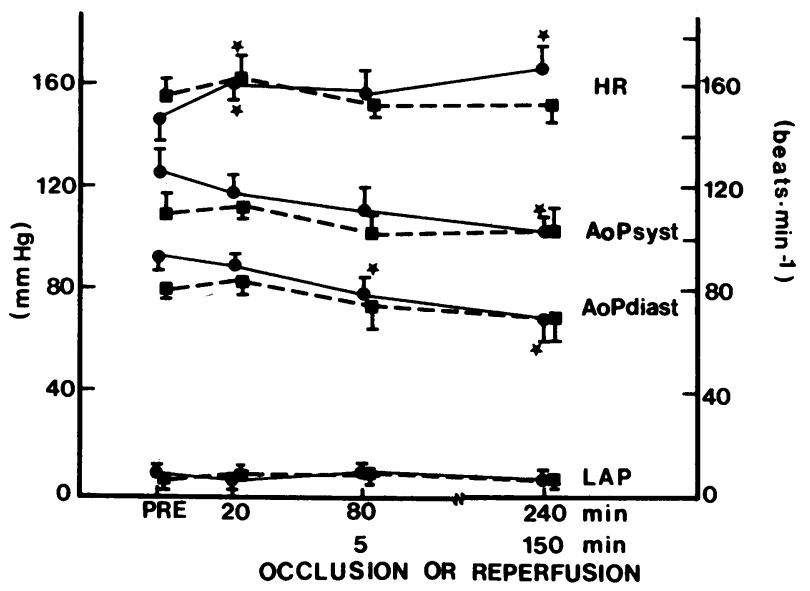

Figure 6. Influence of reperfusion on hemodynamic parameters. \pm , control group with permanent LAD thrombosis; $\bullet$, group infused with rt-PA after $77 \pm 24 \mathrm{~min}$ of LAD thrombosis. Time is expressed relative to the time of LAD occlusion. The values represent mean \pm SEM. AoPsyst, systolic AoP; AoPdiast, diastolic AoP; HR, heart rate. The asterisks indicate a significant difference $(P<0.05)$ versus the preischemic value (PRE).
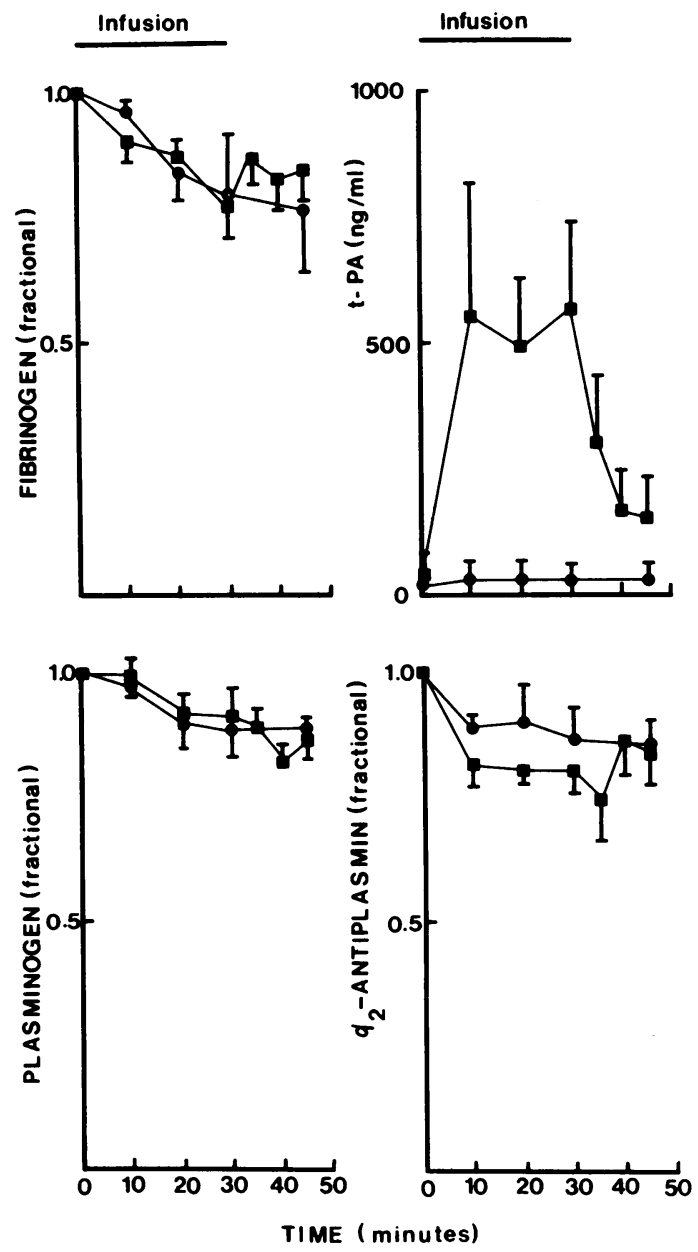

Figure 7. Changes in relevant hemostatic parameters during and after rt-PA infusion. The data represent mean \pm SEM. $\_$, group infused with rt-PA; •, control group. species (19), variable duration of the occlusion, and different methods of determining infarct size. The duration of coronary occlusion, after which reperfusion results in salvage of ischemic myocardium, seems to be species related. In dogs, reperfusion as early as $3 \mathrm{~h}$ resulted in a decrease of ultimate infarction in the majority of reports (10-14), but revascularization after 5 $h$ or later produced either extension of infarction by hemorrhage (15) or no significant change in infarct size (13-15). Collateral circulation in pigs is less extensive than in dogs (19), and an equivalent coronary occlusion producing primarily a subendocardial infarction in the dog, results in a transmural infarct in the pig (20). In contrast to reperfusion in dogs, reperfusion $3 \mathrm{~h}$ after coronary artery occlusion in pigs does not result in any salvage of the area at risk $(16,17)$.

We studied baboons because their coronary anatomy closely resembles that of man $(21,22)$. Thrombolysis was started 30 min to $1 \mathrm{~h}$ after occlusion. Significantly longer occlusion times resulted in extensive myocardial necrosis, even when reperfusion was established. To determine infarct size, we used TTC as a staining technique in a perfusion system to delineate necrotic from viable tissue $(23,24)$. We found a considerable salvage of myocardium at risk after 38-108 min of coronary occlusion and subsequent reperfusion with rt-PA. This agrees with the results of Geary (25), who found an infarct size of $50 \%$ in baboons reperfused after $2 \mathrm{~h}$ of LAD occlusion, in contrast with $94 \%$ in a control group with permanent occlusion. Smith et al. (26) also showed that $50 \%$ of acutely injured myocardium was salvaged with reperfusion after $2 \mathrm{~h}$ of LAD occlusion in monkeys. These authors observed large areas of patchy necrosis surrounding a central infarct. The areas with patchy infarction decreased progressively when reperfusion was postponed from 1 to $6 \mathrm{~h}$ of occlusion while the central zone of infarction gradually augmented. Also, in our study, a clear correlation exists between residual infarction and the duration of occlusion. Recanalization must occur within 90 min of coronary artery occlusion to reduce residual infarct size.

Reperfusion induced macroscopically visible myocardial hemorrhage in the majority of animals in our study. However, the extent of hemorrhage was directly related to the duration of occlusion: significant hemorrhage occurred only in reperfused baboons with coronary occlusion extending beyond $60 \mathrm{~min}$. The extent of hemorrhage increased with increasing occlusion times. This agrees with the findings of Capone et al. (27), who studied myocardial hemorrhage after coronary reperfusion in pigs. In our study, macroscopic assessment of left ventricular slices revealed that hemorrhage was always confined to the zones of necrosis. Several other investigators, using more sophisticated markers of vascular injury and hemorrhage such as the injection of Cr-51-labeled erythrocytes (28) or colloidal carbon suspension (29), or the measurement of tissue hemoglobin concentration (30), also reported that hemorrhage was located within the area of infarction and never extended outside the necrotic zone into viable myocardium. Thus, hemorrhage seems to represent a hallmark of irreversibly damaged tissue. Furthermore, intramyocardial hemorrhage does not affect the healing process of myocardial infarction, in terms of collagen formation (30).

We measured regional myocardial blood flow using the microsphere technique. The limitations of this technique have previously been well reviewed (8). Special problems related to flow studies in infarcted regions include microsphere loss with 
time and swelling of the infarcted region leading to slight underestimation of flow (31). This is also seen in our experiments. The ratio between MBF to the LAD area and the nonLAD area is below $90 \%$ for the pre-ischemic TM injection. Early reflow after thrombolysis showed a reactive hyperemic response in the LAD area in all but two reperfused animals. The so-called "no reflow phenomenon," however, which accompanies reperfusion after 2,6 , and $24 \mathrm{~h}$ of occlusion in the $\operatorname{dog}$ (13), was also observed in six out of nine baboons when measured $150 \mathrm{~min}$ after thrombolysis and despite perfect angiographic refilling.

Our finding that reperfusion causes abnormalities in hemodynamics during the first hours of recanalization is consistent with the findings of other investigators $(25,26,32,33)$. Heyndrickx (34) reported that in dogs subjected to only 15min periods of occlusion followed by reperfusion, regional function in the ischemic zone may take up to $6 \mathrm{~h}$ to normalize. The mechanism by which this depression in contractility occurs has not been clarified.

In accordance with several earlier studies (3, 5-7, 35-37), thrombolysis with rt-PA was not associated with breakdown of the hemostatic system nor with clinically evident bleeding from surgical wounds.

The present results confirm and extend our earlier findings that systemic infusion of rt-PA induces coronary thrombolysis without significant side effects and with salvage of myocardial tissue. Therefore, this substance offers promise for effective and safe thrombolytic therapy of acute myocardial infarction in man.

\section{Acknowledgments}

We thank Genentech Inc., South San Francisco, CA (Dr. C. H. Hoyng, t-PA project team leader) for producing and providing the rt-PA used in this study. The rt-PA was obtained by expression of the human tPA genes in a mammalian cell system. The material is not distinguishable from natural t-PA by a number of biochemical and biological criteria (38).

\section{References}

1. DeWood, M. A., J. Spores, G. R. Hensley, C. S. Simpson, G. S. Engster, K. I. Sutherland, K. P. Grunwald, and J. P. Shields. 1983. Coronary arteriographic findings in acute transmural myocardial infarction. Circulation. 68(Suppl I):39-49.

2. Collen, D., D. C. Rijken, J. Van Damme, and A. Billiau. 1982. Purification of human extrinsic (tissue-type) plasminogen activator in centigram quantities from a human melanoma cell culture fluid and its conditioning for use in vivo. Thromb. Haemostasis. 48:294-296.

3. Bergmann, S. R., K. A. A. Fox, M. M. Ter-Pogossian, B. E. Sobel, and D. Collen. 1983. Clot-selective coronary thrombolysis with tissue-type plasminogen activator. Science (Wash. DC). 220:11811183.

4. Pennica, D., W. E. Holmes, W. J. Kohr, R. N. Harkins, G. A. Vehar, C. A. Ward, W. F. Bennett, E. Yelverton, P. H. Seeburg, H. L. Heyneker, D. V. Goeddel, and D. Collen. 1983. Cloning and expression of human tissue-type plasminogen activator cDNA in E. coli. Nature (Lond.). 301:214-221.

5. Van de Werf, F., S. R. Bergmann, K. A. A. Fox, H. De Geest, C. F. Hoyng, B. E. Sobel, and D. Collen. 1984. Coronary thrombolysis with intravenously administered human tissue-type plasminogen activator produced by recombinant DNA technology. Circulation. 69:605610.
6. Gold, H. K., J. T. Fallon, T. Yasuda, B. A. Khaw, J. L. Guerrero, J. M. Vislosky, R. C. Leinbach, R. Harper, C. Hoyng, E. Grossbard, and D. Collen. 1983. Coronary thrombolysis with recombinant human tissue plasminogen activator. Circulation. 68(Suppl III): 150a. (Abstr.).

7. Collen, D., J. M. Stassen, and M. Verstraete. 1983. Thrombolysis with human extrinsic (tissue-type) plasminogen activator in rabbits with experimental jugular vein thrombosis: effect of molecular form and dose of activator, age of the thrombus, and route of administration. J. Clin. Invest. 71:368-376.

8. Buckberg, G. D., J. C. Luck, D. B. Payne, J. I. E. Hoffman, J. P. Archie, and D. E. Fixler. 1971. Some sources of error in measuring regional blood flow with radioactive microspheres. J. Appl. Physiol. 31:598-604.

9. Schaper, W., W. Flameng, B. Winkler, G. Neugebauer, M. Carl, and S. Pasyk. 1976. Quantification of collateral resistance in acute and chronic experimental coronary occlusion in the dog. Circ. Res. 39:371377.

10. Maroko, P. R., P. Libby, W. R. Ginks, C. M. Bloor, W. E. Shell, B. E. Sobel, and J. Ross, Jr. 1972. Coronary artery reperfusion. I. Early effects on local myocardial function and the extent of myocardial necrosis. J. Clin. Invest. 51:2710-2716.

11. Ginks, W. R., H. D. Sybers, P. R. Maroko, J. W. Covell, B. E. Sobel, and J. Ross, Jr. 1972. Coronary artery reperfusion. II. Reduction of myocardial infarct size at 1 week after the coronary occlusion. $J$. Clin. Invest. 51:2717-2723.

12. Constantini, C., E. Corday, T. W. Lang, S. Meerbaum, J. Brasch, L. Kaplan, S. Rubins, H. Gold, and J. Osher. 1975. Revascularisation after three hours of coronary arterial occlusion. Effects on regional cardiac metabolic function and infarct size. Am. J. Cardiol. 36:368-384.

13. Bloor, C. M., and F. C. White. 1975 . Coronary artery reperfusion. Effects of occlusion duration on reactive hyperemia responses. Basic Res. Cardiol. 70:148-158.

14. Mathur, V. S., G. A. Guinn, and W. H. Burris. 1975. Maximal revascularization (reperfusion) in intact conscious dogs after 2 to 5 hours of coronary occlusion. Am. J. Cardiol. 36:252-261.

15. Bresnahan, G. R., R. Roberts, W. E. Shell, J. Ross, Jr., and B. E. Sobel. 1974. Deleterious effects due to hemorrhage after myocardial infarction. Am. J. Cardiol. 33:82-86.

16. Althaus, U., J. Janett, E. Scholl, and H. Riedwyl. 1976. Effects of myocardial revascularization following acute coronary occlusion in pigs. Eur. J. Clin. Invest. 6:7-15.

17. Campbell, C. D., Y. Takanashi, J. Laas, P. Meus, R. Pick, and R. L. Replogle. 1981. Effect of coronary artery reperfusion on infarct size in swine. J. Thorac. Cardiovasc. Surg. 81:288-296.

18. Schwarz, F., H. O. Wagner, M. Sesto, M. Hofmann, W. Schaper, and W. Kübler. 1982. Native collaterals in the development of collateral circulation after chronic coronary stenosis in mongrel dogs. Circulation. 66:303-308.

19. Schaper, W. 1971. The morphology of collaterals and anastomoses in human, canine and porcine hearts. In The Collateral Circulation of the Heart. D. A. K. Black, editor. Elsevier/North Holland, Amsterdam. 5-18.

20. Fozzard, H. A. 1975. Validity of myocardial infarction models. Circulation. 52(Suppl III):131-146.

21. Lubbe, W. F., M. Peisach, R. Pretorius, K. Bruyneel, and L. H. Opie. 1974. Distribution of myocardial blood flow before and after coronary artery ligation in the baboon. Relation to early ventricular fibrillation. Cardiovasc. Res. 8:478-487.

22. Crozatier, B., J. Ross, Jr., D. Franklin, C. M. Bloor, F. C. White, H. Tomoike, and D. P. McKown. 1978. Myocardial infarction in the baboon: regional function and the collateral circulation. Am. J. Physiol. 235:H413-421.

23. Fishbein, M. C., S. Meerbaum, J. Rit, U. Lando, K. Kanmasuse, J. C. Mercier, E. Corday, and W. Ganz. 1981. Early phase acute myocardial infarct size quantification: validation of the triphenyl 
tetrazolium chloride tissue enzyme staining technique. Am. Heart $J$. 101:593-600.

24. Taylor, A. L., M. Wyman, and B. Healy Bulkley. 1983. Early infarct delineation in reperfused and nonreperfused myocardial by Triphenyl Tetrazolium Chloride Stain. Circulation. 68:(Suppl. III)779.

25. Geary, G. G., G. T. Smith, and J. J. McNamara. 1982. Quantitative effect of early coronary artery reperfusion in baboons. Extent of salvage of the perfusion bed of an occluded artery. Circulation. 66:391-396.

26. Smith, G. T., J. R. Soeter, H. H. Haston, and J. J. McNamara. 1974. Coronary reperfusion in primates: serial electrocardiographic and histologic assessment. J. Clin. Invest. 54:1420-1427.

27. Capone, R. J., and A. S. Most. 1978. Myocardial hemorrhage after coronary reperfusion in pigs. Am. J. Cardiol. 41:259-266.

28. Higginson, L. A. J., F. White, H. A. Heggtweit, T. M. Sanders, C. M. Bloor, and J. W. Covell. 1982. Determinants of myocardial hemorrhage after coronary reperfusion in the anesthetized dog. Circulation. 65:62-69.

29. Fishbein, M. C., J. Y. Rit, U. Lando, K. Kanmatsuse, J. C. Mercier, and W. Ganz. 1980. The relationship of vascular injury and myocardial hemorrhage to necrosis after reperfusion. Circulation. 62:1274-1279.

30. Roberts, C. S., B. A. Frederick, J. Schoen, and R. A. Kloner. 1983. Effect of coronary reperfusion on myocardial hemorrhage and infarct healing. Am. J. Cardiol. 52:610-614.

31. Reimer, K. A., and R. B. Jennings. 1979. The changing anatomic reference base of evolving myocardial infarction. Underestimation of myocardial collateral blood flow and overestimation of experimental anatomic infarct size due to tissue edema, hemorrhage and acute inflammation. Circulation. 60:866-876.

32. White, F. C., T. M. Sanders, and C. M. Bloor. 1978. Regional redistribution of myocardial blood flow after coronary occlusion and reperfusion in the conscious dog. Am. J. Cardiol. 42:234-243.

33. Lang, T. W., E. Corday, H. Gold, S. Meerbaum, S. Rubins, C. Constantini, S. Hirose, J. Osher, and V. Rosen. 1974. Consequences of reperfusion after coronary occlusion. Effects of hemodynamic and regional myocardial metabolic function. Am. J. Cardiol. 33:69-81.

34. Heyndrickx, G. R., R. W. Millard, R. J. McRitchie, P. R. Maroko, and S. F. Vatner. 1975. Regional myocardial functional and electrophysiological alterations after brief coronary artery occlusion in conscious dogs. J. Clin. Invest. 56:978-985.

35. Matsuo, O., D. C. Rijken, and D. Collen. 1981. Thrombolysis by human tissue plasminogen activator and urokinase in rabbits with experimental pulmonary embolus. Nature (Lond.). 291:590-591.

36. Korninger, C., O. Matsuo, R. Suy, J. M. Stassen, and D. Collen. 1982. Thrombolysis with human extrinsic (tissue-type) plasminogen activator in dogs with femoral vein thrombosis. J. Clin. Invest. 69:573-580.

37. Weimar, W., J. Stibbe, A. J. van Seyen, A. Billiau, P. De Somer, and D. Collen. 1981. Specific lysis of an iliofemoral thrombus by administration of extrinsic (tissue-type) plasminogen activator. Lancet. II:1018-1020.

38. Collen, D., J. M. Stassen, B. J. Marafino, Jr., S. Builder, F. De Cock, J. Ogez, D. Tajiri, D. Pennica, W. F. Bennett, J. Salwa, and C. F. Hoyng. 1984. Biological properties of human tissue-type plasminogen activator obtained by expression of recombinant DNA in mammalian cells. J. Pharmacol. Exp. Ther. 231:146-152. 